\title{
Alginate Synthesis in Mucoid Pseudomonas aeruginosa: a Chromosomal Locus Involved in Control
}

\author{
By JANET A. M. FYFE* AND JOHN R. W. GOVAN \\ Department of Bacteriology, University of Edinburgh, Medical School, Teviot Place, \\ Edinburgh EH8 $9 A G$
}

(Received 10 December 1979; revised 17 February 1980)

\begin{abstract}
Mucoid variants of Pseudomonas aeruginosa isolated in vitro or in vivo could be classified into two phenotypic groups based on whether alginate was produced on a chemically defined medium. Mucoid strains yielded lower recombination frequencies than the nonmucoid parent when used as donors in FP2-mediated plate matings. The mucoid characteristic $(m u c)$ was co-inherited by a proportion of recombinants selected for the inheritance of chromosomal markers his-5075+ or cys-5605+. The results of further experiments using either a mucoid recipient or a mucoid donor carrying plasmid R68.45 suggested that the control of alginate production in $P$. aeruginosa involves at least one chromosomal locus.
\end{abstract}

\section{INTRODUCTION}

Mucoid strains of Pseudomonas aeruginosa are frequently associated with chronic pulmonary infections in patients with cystic fibrosis (CF), but are rarely encountered in nature or in other clinical situations (Doggett, 1969). Doggett et al. (1966) reported that the nonmucoid form of $P$. aeruginosa precedes the mucoid form in the CF lung, but the latter eventually predominates and is associated with clinical deterioration. Mucoid and nonmucoid strains isolated from the same patient have been shown to belong to the same pyocin type (Williams \& Govan, 1973) and serotype (Diaz et al., 1970) suggesting that they are variants of the same strain.

Several explanations have been proposed for the emergence of mucoid strains in vivo. These include induction by phage (Martin, 1973) and selection of a mutant by prolonged antibiotic therapy or some other factor (Doggett \& Harrison, 1969; Govan \& Fyfe, 1978). Markowitz et al. (1978) suggested that the genetic basis of alginate production by mucoid $P$. aeruginosa may be plasmid-determined, but concluded that there was no evidence for this.

In Escherichia coli $\mathrm{K} 12$, capsular polysaccharide production is controlled by three regulator genes, $C a p R, C a p S$ and $C a p T$. Mutations in any of these loci result in a mucoid phenotype, and mapping studies have shown them to be situated in three distinct regions of the chromosome (Hua \& Markovitz, 1972).

We have previously reported that mucoid variants of $P$. aeruginosa strain PAO and other non-mucoid strains can be isolated in vitro by selecting for carbenicillin resistance (Govan \& Fyfe, 1978) or resistance to a virulent phage (Govan, 1975), and that the exopolysaccharide produced by such variants is an alginate-like polymer, similar to that produced by clinical isolates. The ability to produce alginate is transferable between strains of $P$. aeruginosa by conjugation (Govan, 1976; Fyfe \& Govan, 1978).

This paper reports further studies on the genetic basis of alginate production in $P$. aeruginosa using mucoid derivatives of genetically marked PAO strains. 


\section{Table 1. Strains of Pseudomonas aeruginosa used in this study}

\begin{tabular}{|c|c|}
\hline Strain & Genotype* \\
\hline $\begin{array}{l}\text { PAO8 } \\
\text { PAO381 } \\
\text { PAO568 }\end{array}$ & $\begin{array}{l}\text { met-28 ilv-202 str-1, FP- } \\
\text { leu-38 str-2, FP2 }{ }^{+} \\
\text {leu-38 str-2 muc- } 2, \mathrm{FP} 2^{+}\end{array}$ \\
\hline PAO578 & leu-38 str-2 muc-22, FP2 ${ }^{+}$ \\
\hline PAO579 & leu-38 str-2 muc-23, $\mathrm{FP}^{+}$ \\
\hline PAO581 & leu-38 str-2 muc-25, $\mathrm{FP}^{+}$ \\
\hline PAO2018 & $\begin{array}{l}\text { met-28 ilv-202 str-1 muc-35, } \\
\text { FP- }^{-}\end{array}$ \\
\hline PAO2020 & $\begin{array}{l}\text { cys-5605 arg A171 pro- } 67 \\
\text { his-52 nal-25, FP- }\end{array}$ \\
\hline PAO2021 & $\begin{array}{l}\text { cys-5605 his-5075 arg A171 } \\
\text { pro-67 nal-25 muc-36, } \mathrm{FP}^{-}\end{array}$ \\
\hline PAO2022 & $\begin{array}{l}\text { cys-5605 his-5075 arg A171 } \\
\text { pro-67 nal-25, FP- }\end{array}$ \\
\hline PAO2023 & $\begin{array}{l}\text { cys-5605 his-5075 arg A171 } \\
\text { pro-67 nal-25 car-10, } \mathrm{FP}^{-}\end{array}$ \\
\hline$\Delta$ & $\begin{array}{l}\text { his-5075 arg A171 pro-67 } \\
\text { nal-25 muc-35, } \text { FP- }^{-}, \mathrm{R}^{-}\end{array}$ \\
\hline
\end{tabular}

Isaac \& Holloway (1968)

Stanisich \& Holloway (1969)

Mucoid derivative of PAO381 isolated following incubation

with phage M6 (Govan, 1975)

Mucoid derivative of PAO381 isolated by the method of Govan \& Fyfe (1978)

Mucoid derivative of PAO381 isolated by the method of Govan \& Fyfe (1978)

Mucoid derivative of PAO381 isolated following incubation with phage E79 (Govan, 1975)

Mucoid derivative of PAO8 isolated by the method of Govan \& Fyfe (1978)

His ${ }^{-}$derivative of a his-5075+ transductant of PAO2022

Mucoid derivative of PAO2022 isolated by the method of Govan \& Fyfe (1978)

Pro- $^{-}$NAL $^{\mathrm{r}}$ derivative of PAO540 (Haas et al., 1977)

Car- derivative of PAO2022

$\underset{\text { PAO2022 }}{\text { Mucoid } \text { Cys }^{+}}$recombinant from PAO2018(R68.45) $\times$

* The genotype symbols designate the following: arg, arginine; car, carbamoylphosphate synthase; cys, cysteine; his, histidine; ilv, isoleucine/valine; leu, leucine; met, methionine; muc, mucoid (alginate-producing); nal, nalidixic acid resistance; pro, proline; str, streptomycin resistance. $\mathrm{FP}^{-}, \mathrm{R}^{-}$, recipient strain; FP2 ${ }^{+}$, donor strain carrying the sex factor FP2.

\section{METHODS}

Bacteria and bacteriophage. The PAO strains used in this study are shown in Table 1. Donor strains carrying the plasmid R68.45 were constructed according to Haas \& Holloway (1976). Nalidixic acidresistant mutants were isolated according to Haas \& Holloway (1976). Phage F116L (Krishnapillai, 1971) was used for all transductions. Phage PR4 (Stanisich, 1974) was used in the isolation of strains which had lost R68.45. Phages E79 and M6, obtained from Professor B. W. Holloway, were used in the isolation of mucoid strains using the method of Govan (1975). Clinical strains of mucoid $P$. aeruginosa were obtained from patients attending the CF clinic at the Royal Hospital for Sick Children, Edinburgh and were supplied by Dr Kenneth Watson.

Media and cultural conditions. Nutrient Broth (NB) was Oxoid no. 2 supplemented with $0.5 \%$ (w/v) yeast extract (Oxoid), Pseudomonas Isolation Agar (PIA) was from Difco and Minimal Agar (MA) was as described by Vogel \& Bonner (1956). Amino acid supplements were used at a concentration of $1 \mathrm{~mm}$, $50 \mathrm{~mm}$ stock solutions being kept over chloroform. Antibiotics used were carbenicillin (Pyopen; Beecham), kanamycin (Bristol Laboratories), tetracycline (Glaxo) and nalidixic acid (NAL) (Winthrop).

Broth cultures were grown in McCartney bottles on an orbital incubator (Gallenkamp) at $140 \mathrm{rev} . \mathrm{min}^{-1}$, and all cultures were incubated at $37^{\circ} \mathrm{C}$.

Transductions were performed according to the method of Krishnapillai (1971).

Plate matings were performed as described by Stanisich \& Holloway (1972).

Interrupted matings were performed as described by Haas et al. (1977).

Recombinant analysis. This was performed to determine the percentage co-inheritance of unselected markers. For each selected marker, 100 recombinants were purified by streaking on to fresh selective MA. Inheritance of unselected auxotrophic markers was scored by transferring recombinants to appropriately supplemented MA. Inheritance of $m u c$ or $m u c^{+}$was scored by transferring the recombinants to PIA, except for matings using the donors PAO579 and PAO581. In these cases, mucoid recombinants could be recognized on the mating plates, and transfer to PIA before scoring made no difference to the result obtained. 


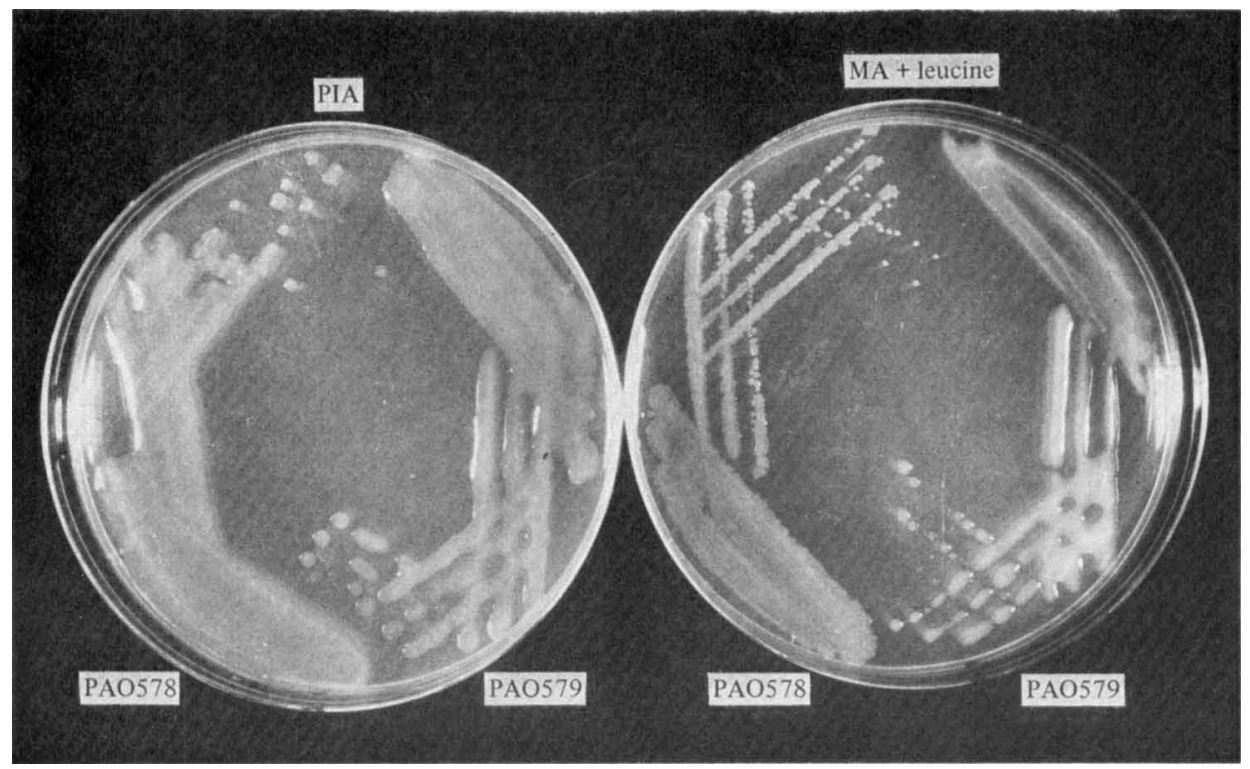

Fig. 1. Phenotypic differences between two mucoid variants of PAO381. Strains PAO578 and PAO579 after $24 \mathrm{~h}$ incubation on PIA and MA + leucine: PAO579 produces copious alginate under both conditions, whereas PAO578 appears rough and non-mucoid on MA+leucine.

\section{RESULTS}

\section{Phenotypic differences between mucoid strains}

The mucoid strains investigated produced copious exopolysaccharide on PIA after $24 \mathrm{~h}$ incubation and resembled colonial type 5 described by Phillips (1969); they could be readily distinguished from the slimy growth often observed following extended incubation of $P$. aeruginosa in media containing high concentrations of carbohydrate. However, when 100 independent, spontaneous mucoid derivatives of PAO381 were cultured on MA (+ leucine), only $40 \%$ were mucoid after $24 \mathrm{~h}$, while the remaining $60 \%$ appeared rough and nonmucoid; when transferred back to PIA, the two groups were both mucoid. Strains PAO579 and PAO581 are examples of the first category (group 1) and PAO568 and PAO578 are examples of the second group (group 2). Figure 1 shows PAO578 and PAO579 after $24 \mathrm{~h}$ incubation on PIA and MA + leucine.

Mucoid strains isolated from the sputa of patients with cystic fibrosis could also be classified into groups 1 and 2, and in several cases appeared concurrently in the same specimen.

\section{Mucoid strains as donors and recipients in $\mathrm{FP2}$-mediated plate matings}

Figure 2 is a chromosome map of $P$. aeruginosa PAO showing the locations of markers relevant to this study. To examine the effect of alginate production on chromosome transfer, a series of plate matings was performed using mucoid strains as donors or recipients.

Table 2 shows the recombination frequencies obtained using the non-mucoid recipient strain PAO2022 and the mucoid donors PAO568, PAO578, PAO579 and PAO581. Strain PAO381 was included as a control donor. The mucoid donors yielded lower recombination frequencies than PAO381 for all selected markers. Non-mucoid revertants of these strains had recovered donor ability, giving recombination frequencies equivalent to those obtained using PAO381.

When mucoid derivatives of PAO2022 were used as recipients in plate matings with PAO381, recombination frequencies were similar to those obtained in the PAO381 $\times$ PAO2022 mating. Hence alginate production does not impair recipient ability. 


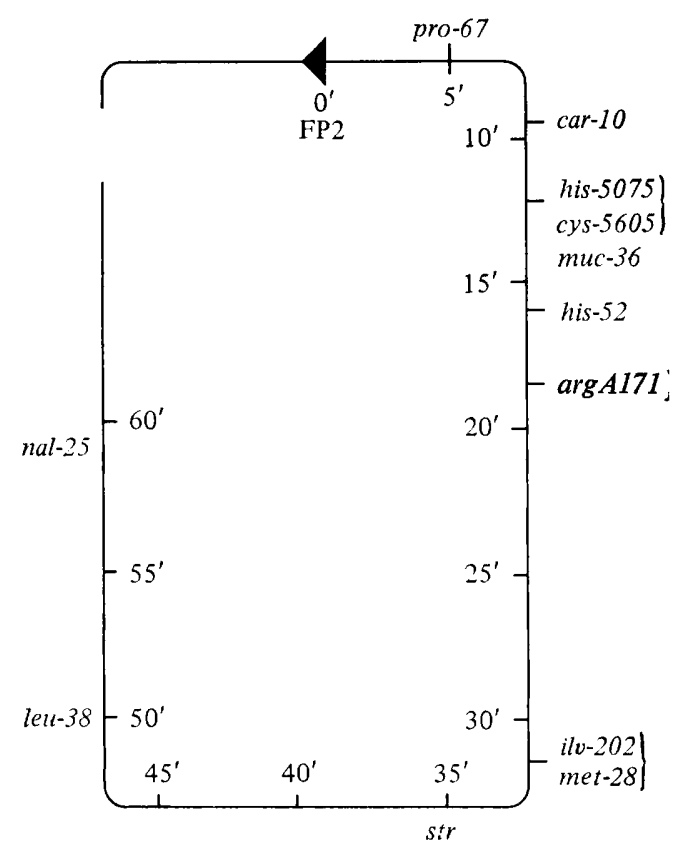

Fig. 2. Chromosome map of $\boldsymbol{P}$. aeruginosa strain PAO showing the markers relevant to this study (based on Holloway et al., 1979). See legend to Table 1 for genotype symbols. Very close linkage exists between the following pairs of markers: pro-67 and proB, car-10 and car-9, his-5075 and hisI, his-52 and hisII.

Table 2. Frequency of recombinants obtained in plate matings between PAO2022 and mucoid derivatives of PAO381

\begin{tabular}{|c|c|c|c|c|c|}
\hline \multirow[b]{2}{*}{ Selected marker } & \multicolumn{5}{|c|}{ No. of recombinants per $10^{8}$ donors } \\
\hline & $\times$ PAO381 & $\times$ PAO568 & $\times$ PAO578 & $\times$ PAO579 & $\times$ PAO581 \\
\hline pro- $67^{+}$ & 1186 & 25 & 81 & 13 & 47 \\
\hline his-5075+ & 98 & 9 & 14 & 3 & 17 \\
\hline cys- $5605^{+}$ & 81 & 7 & 8 & 2 & 9 \\
\hline $\arg \mathrm{AlT1}^{+}$ & 958 & 100 & 108 & 36 & 119 \\
\hline
\end{tabular}

Co-inheritance of muc with his-5075 and cys-5605

Examination of the recombinants from the PAO579 $\times$ PAO2022 and PAO581 $\times$ PAO2022 matings revealed mixtures of mucoid and non-mucoid clones. All the recombinants from the matings using PAO568 and PAO578 appeared non-mucoid on the selection plates. However, when purified and replica-plated to PIA, a proportion was mucoid.

Table 3 shows the percentage co-inheritance of alginate production with each of the selected markers in these plate matings. All mucoid clones from the mating plates were checked for $\mathrm{NAL}^{r}$ to ensure that they were recombinants and not $l e u^{+}$revertants of the donors.

In a reciprocal plate mating between a non-mucoid donor strain (PAO381) and a group 2 mucoid recipient (PAO2021), co-inheritance of $m u c-36^{+}$(non-mucoid) with his-5075+ and cys-5605+ was observed. Analysis of recombinants (outlined in Table 4) indicated a location for $m u c-36$ distal to cys-5605 rather than between his-5075 and pro-67, since the co-inheritance of $\mathrm{muc}^{+}$by $\mathrm{cys}^{+} \mathrm{pro}^{+}$and $\mathrm{his}^{+} \mathrm{pro}^{+}$double recombinants was low. However, low co-inheritance of muc, his and cys was obtained when the selected marker was $\arg A 171$. 

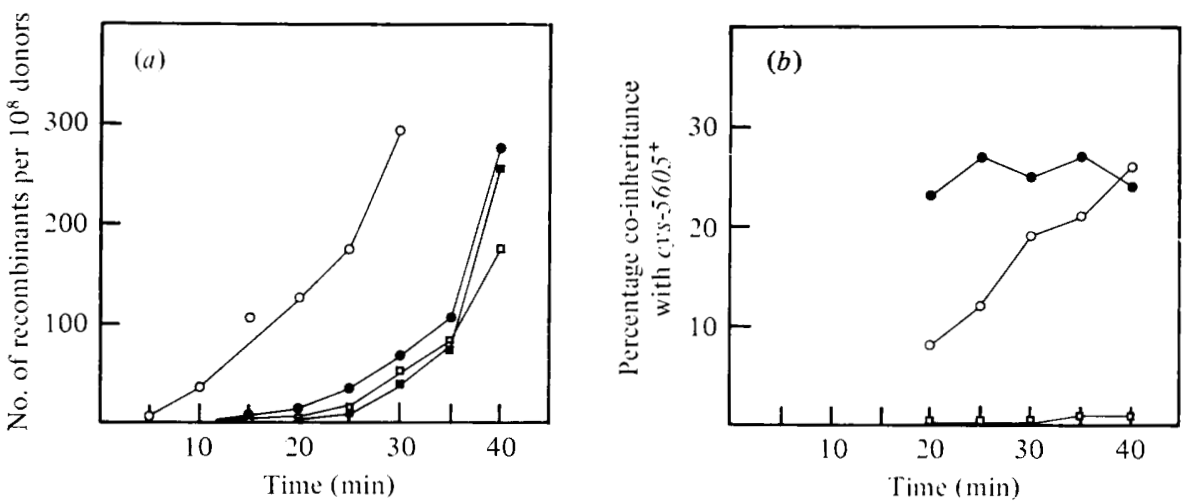

Fig. 3. Interrupted mating between PAO381 and the mucoid recipient PAO2021. (a) Time of entry

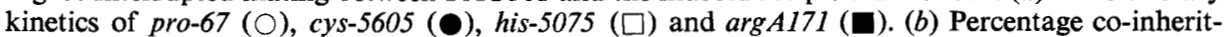
ance with cys-5605+ of the unselected markers $m u c-36^{+}(\bigcirc)$, pro- $67^{+}(\bigcirc)$ and $\arg A 171^{+}(\square)$.

Table 3. Co-inheritance of muc mutations with selected auxotrophic markers following plate matings between mucoid donors and the non-mucoid recipient PAO2022

Percentage of recombinants co-inheriting muc

\begin{tabular}{|c|c|c|c|c|}
\hline Donor & pro- $67^{+}$ & his-5075+ & cys- $5605^{+}$ & $\arg A 171^{+}$ \\
\hline PAO568 (muc-2) & 1 & 21 & 15 & $<1$ \\
\hline PAO578 (muc-22) & 1 & 11 & 11 & $<1$ \\
\hline PAO579 (mис-23) & 2 & 21 & 32 & $<1$ \\
\hline PAO581 (muc-25) & $<1$ & 7 & 14 & $<1$ \\
\hline
\end{tabular}

Table 4. Recombinant analysis following a plate mating between PAO381 and the mucoid recipient PAO2021

\begin{tabular}{|c|c|c|c|c|c|c|}
\hline \multirow{2}{*}{$\begin{array}{c}\text { Selected } \\
\text { marker }\end{array}$} & \multirow{2}{*}{$\begin{array}{l}\text { No. of } \\
\text { recombinants } \\
\text { per } 10^{8} \text { donors }\end{array}$} & \multicolumn{5}{|c|}{ Percentage co-inheritance of unselected marker } \\
\hline & & $m u c-36^{+}$ & pro- $67^{+}$ & his-5075+ & cys- $5605^{+}$ & $\arg A 171^{+}$ \\
\hline pro- $67^{+}$ & 2182 & 1 & - & 2 & 2 & 1 \\
\hline his $-5075^{+}$ & 164 & 15 & 34 & - & 90 & 2 \\
\hline cys $-5605^{+}$ & 155 & 18 & 30 & 93 & - & 1 \\
\hline $\arg A 171^{+}$ & 1273 & $<1$ & $<1$ & $<1$ & $<1$ & - \\
\hline
\end{tabular}

So confirmation of the proposed location of muc-36 could not be obtained by the analysis of $\mathrm{arg}^{+} \mathrm{cys}^{+}$and $\mathrm{arg}^{+} \mathrm{his}^{+}$double recombinants.

Co-inheritance of unselected auxotrophic markers was not affected by alginate production by either the donor or recipient in these plate matings.

\section{Transfer of muc-36+ during an interrupted mating}

To obtain further evidence for the location of muc-36 distal to cys-5605 an interrupted mating was performed between PAO381 and PAO2021 (Fig. 3). Time of entry kinetics displayed by the selected markers pro- $67^{+}$, his-5075+, cys-5605+ and $\operatorname{arg~} 1171^{+}$(Fig. $3 a$ ) were consistent with the published order and times of entry for these loci (Holloway et al., 1979). The transfer of $m u c-36^{+}$could not be measured directly as a selection procedure is not available. However, the $\mathrm{cys}^{+}$recombinants obtained at each interruption time were scored for co-inberitance of $\mathrm{muc}^{+}$as well as the proximal marker $\mathrm{pro}^{+}$and the distal marker $\mathrm{arg}^{+}$ (Fig. $3 b$ ). The percentage co-inheritance of pro $^{+}$by $c y s^{+}$recombinants was approximately $25 \%$, irrespective of the interruption time. Conversely, the percentage co-inheritance of $m u c^{+}$increased significantly with mating time, indicating a time of entry later than for cys. 
Table 5. Recombinant analysis following a plate mating between PAO2018(R68.45) and PAO2022

\begin{tabular}{|c|c|c|c|c|c|c|}
\hline \multirow{2}{*}{$\begin{array}{l}\text { Selected } \\
\text { marker }\end{array}$} & \multirow{2}{*}{$\begin{array}{l}\text { No. of } \\
\text { recombinants } \\
\text { per } 10^{8} \text { donors }\end{array}$} & \multicolumn{5}{|c|}{ Percentage co-inheritance of unselected marker } \\
\hline & & $m u c-35$ & pro- $67^{+}$ & his-5075+ & cys $-5605^{+}$ & $\arg A 171^{+}$ \\
\hline pro- $67^{+}$ & 3000 & 6 & - & 43 & 42 & 3 \\
\hline his-5075+ & 4100 & 16 & 49 & - & 92 & 2 \\
\hline cys- $5605^{+}$ & 5600 & 22 & 46 & 93 & - & 4 \\
\hline $\arg A 171^{+}$ & 19000 & 2 & 13 & 10 & 8 & - \\
\hline
\end{tabular}

Table 6. Recombinant analysis following a plate mating between PAO8(R68.45) and PAO2050

\begin{tabular}{|c|c|c|c|c|c|}
\hline \multirow{2}{*}{$\begin{array}{c}\text { Selected } \\
\text { marker }\end{array}$} & \multirow{2}{*}{$\begin{array}{l}\text { No. of } \\
\text { recombinants } \\
\text { per } 10^{8} \text { donors }\end{array}$} & \multicolumn{4}{|c|}{ Percentage co-inheritance of unselected marker } \\
\hline & & muc- $35^{+}$ & pro- $67^{+}$ & his-5075+ & $\arg A 171^{+}$ \\
\hline pro- $67^{+}$ & 1500 & 5 & - & 31 & 2 \\
\hline his-5075+ & 3100 & 26 & 49 & - & 7 \\
\hline $\arg \mathrm{Al71}^{+}$ & 17000 & 3 & 7 & 4 & - \\
\hline
\end{tabular}

However, low co-inheritance of $\arg ^{+}$was again obtained, and when the $\arg ^{+}$recombinants were scored for $\mathrm{cys}^{+}$and $m u c^{+},<1 \%$ co-inheritance was observed.

\section{Mapping muc-35 using R68.45}

In a further attempt to map a muc locus unambiguously, a series of plate matings was performed using donor strains carrying R68.45. The group 2 mucoid strain PAO2018 (R68.45) was crossed with PAO2022, and the recombination frequencies and co-inheritance of unselected markers are shown in Table 5. One of the $c y s^{+}$recombinants from this mating had inherited muc-35 and R68.45, but was still pro his arg. Strain PAO2050 was derived from this recombinant by isolating a clone resistant to the phage PR4. This clone had acquired sensitivity to carbenicillin, tetracycline and kanamycin and could act as a recipient for R68.45. Hence, it was concluded that PAO2050 was an R-derivative of the original $c \mathrm{~s}^{+}$recombinant. A plate mating was performed between PAO8(R68.45) and PAO2050 in which $m u c-35$ was a recipient marker rather than a donor marker, as in the previous mating. The results are shown in Table 6.

\section{Linkage of muc-35 to other markers}

Since $m u c$-35 showed linkage to his-5075 and cys-5605 in R68.45-mediated plate matings, it was expected that co-inheritance of $m u c-35$ would also be observed with other markers in the 8 to $15 \mathrm{~min}$ region of the PAO chromosome. Hence, plate matings were performed using PAO2018(R68 .45) as donor and the non-mucoid recipient strains PAO2020 (pro-67 cys-5605 his-52 arg A171) and PAO2023 (pro-67 car-10 his-5075 cys-5605 arg A171). Recombinant analysis following these matings indicated that co-inheritance of muc-35 with his-52 and car-10 was low ( $3 \%$ in each case).

Attempts to isolate new auxotrophic markers in the 8 to $15 \mathrm{~min}$ region were unsuccessful.

\section{DISCUSSION}

The mucoid PAO strains and mucoid strains of $P$. aeruginosa isolated from CF patients could be divided into two major groups based on alginate production or non-production on MA after $24 \mathrm{~h}$ at $37^{\circ} \mathrm{C}$. Further characterization of these strains should reveal the extent of phenotypic variation and lead to an understanding of the nature of the control system.

Production or non-production of alginate cannot be selected for in plate or interrupted 
mating experiments. As in the case of $E$. coli, the mucoid determinants can only be mapped indirectly by measuring co-inheritance with markers which can be selected for. Markovitz et al. (1967) used this method to show that CapS, a mutation resulting in mucoidness of $E$. coli $\mathrm{K} 12$, was located on the chromosome near a $\operatorname{tr} p$ gene. They performed a series of interrupted and uninterrupted matings between a non-mucoid donor $\left(\operatorname{trp}^{+} \mathrm{CapS}^{+} \mathrm{Hfr}\right)$ and a mucoid recipient (trp CapS) screening the $\operatorname{tr} p^{+}$recombinants for co-inheritance of $\mathrm{CapS}^{+}$.

Our initial experiments with $P$. aeruginosa using mucoid donors (FP2 ${ }^{+}$) showed that four, independently isolated $m u c$ mutations could be transferred to a non-mucoid recipient by selecting for the inheritance of chromosomal markers cys-5605 and his-5075. Similar results were obtained when PAO381 was crossed with a mucoid recipient, PAO2021. However, more precise mapping of the mucoid determinant (muc-36) proved difficult because of linkage anomalies between the selected markers. The segregation data in Table 4 and the results of the interrupted mating (Fig. 3) serve to illustrate this problem. Although arg A171 enters approximately $7 \mathrm{~min}$ after his-5075 and cys-5605, arg $^{+}$recombinants show no coinheritance of the earlier markers.

Low linkage between markers with similar times of entry has been previously described in PAO, and several hypotheses have been put forward to explain this observation. These included the 'two linkage group' theory (Stanisich \& Holloway, 1969; Loutit, 1969) and the 'two origin' hypothesis (Holloway et al., 1975); however, insufficient evidence has been obtained to support either of these alternatives. The development of an improved technique for FP2-mediated interrupted matings (Haas et al., 1977) and the introduction of R68.45 into PAO genetics have provided alternative approaches to chromosome mapping in $P$. aeruginosa.

We attempted to map muc-35 by means of R68.45-mediated plate matings; however, the results were essentially the same as those obtained using FP2.

A possible explanation for the low linkage between $\arg A 171$ and the proximal markers in our experiments could be that the recipient strain PAO2022 was derived from PAO540, which had been mutagenized with $N$-methyl- $N^{\prime}$-nitro- $N$-nitrosoguanidine on two occasions. However, this is unlikely because we have obtained similar results using PAT strains with comparable markers.

Despite these anomalies, which are not in themselves associated with alginate production in $P$. aeruginosa strain PAO, this investigation has shown that all the muc mutations examined are linked to the chromosomal markers pro-67, his-5075 and cys-5605, and that at least one, $m u c-36$, is distal to $c y s-5605$ and probably at about 14 min. A catabolic marker, puuB, is also reported to be in the 14 min region (Matsumoto et al., 1978) but we have not yet determined whether muc-36 is closely linked to this locus.

Before the number of genes involved in the control of alginate production can be determined, a closely linked marker will need to be found which can be selected for in matings and transductions.

We wish to thank Dr S. G. B. Amyes for valuable discussions during preparation of the manuscript. This work was supported by a research grant from the Jeffrey Charitable Trust in association with the Cystic Fibrosis Research Trust.

\section{REFERENCES}

Diaz, F., Mosovich, L. L. \& Neter, E. (1970). Serogroups of Pseudomonas aeruginosa and the immune response of patients with cystic fibrosis. Journal of Infectious Diseases 121, 269-274.

Dogget, R. G. (1969). Incidence of mucoid Pseudomonas aeruginosa from clinical sources. Applied Microbiology 18, 936-937.

Doggeti, R. G. \& Harrison, G. M. (1969). Signi- ficance of the pulmonary flora associated with chronic pulmonary disease in cystic fibrosis. In Proceedings of the 5th International Cystic Fibrosis Conference, pp. 175-188. Edited by D. Lawson. London: Cambridge Press.

Doggett, R. G., Harrison, G. M., Stillwell, R. N. \& Wallis, E. S. (1966). An atypical Pseudomonas aeruginosa associated with cystic fibrosis of the pancreas. Journal of Pediatrics 68, 215-221. 
Fyfe, J. A. M. \& Govan, J. R. W. (1978). A genetic approach to the study of mucoid Pseudomonas aeruginosa. Proceedings of the Society for General Microbiology 5, 54.

Govan, J. R. W. (1975). Mucoid strains of Pseudomonas aeruginosa: the influence of culture medium on the stability of mucus production. Journal of Medical Microbiology 8, 513-522.

GovaN, J. R. W. (1976). Genetic studies on mucoid Pseudomonas aeruginosa. Proceedings of the Society for General Microbiology 3, 187.

Govan, J. R. W. \& Fyfe, J. A. M. (1978). Mucoid Pseudomonas aeruginosa and cystic fibrosis: resistance of the mucoid form to carbenicillin, flucloxacillin and tobramycin and the isolation of mucoid variants in vitro. Journal of Antimicrobial Chemotherapy 4, 233-240.

HaAs, D. \& Holloway, B. W. (1976). R factor variants with enhanced sex-factor activity in Pseudomonas aeruginosa. Molecular and General Genetics 144, 243-251.

haAs, D., Holloway, B. W., Schamböck, A. \& LeISINGER, TH. (1977). The genetic organization of arginine biosynthesis in Pseudomonas aeruginosa. Molecular and General Genetics 154, 7-22.

Holloway, B. W., Chandler, P., Krishnapillai, V., Mills, B., Rossiter, H., Stanisich, V. \& WATSON, J. (1975). Genetic basis of drug resistance in Pseudomonas aeruginosa. In Drug-inactivating Enzymes and Antibiotic Resistance, pp. 271-286. Edited by S. Mitsuhashi, L. Rosival \& V. Krcmery. Berlin: Springer-Verlag.

Holloway, B. W., Krishnapillai, V. \& Morgan, A. F. (1979). Chromosomal genetics of Pseudomonas. Microbiological Reviews 43, 73-102.

Hua, S. S. \& Markovitz, A. (1972). Multiple regulator gene control of the galactose operon in Escherichia coli K12. Journal of Bacteriology 110, 1089-1099.

IsAAC, J. H. \& Holloway, B. W. (1968). Control of pyrimidine biosynthesis in Pseudomonas aeruginosa. Journal of Bacteriology 96, 1732-1741.

KrishNaPILlaI, V. (1971). A novel transducing phage: its role in recognition of a possible new host-controlled modification system in Pseudo- monas aeruginosa. Molecular and General Genetics 114, 134-143.

Loutit, J. S. (1969). Investigation of the mating system of Pseudomonas aeruginosa strain 1. IV. Mapping of distal markers. Genetical Research 13, 91-98.

Markovitz, A., Lieberman, M. \& Rosenbaum, N. (1967). Derepression of phosphomannose isomerase by regulator gene mutations involved in capsular polysaccharide synthesis in Escherichia coli K-12. Journal of Bacteriology 94, 1497-1501.

Markowitz, S. M., Macrina, F. L. \& Phibbs, P. V. (1978). R factor inheritance and plasmid content in mucoid Pseudomonas aeruginosa. Infection and Immunity 22, 530-539.

Martin, D. R. (1973). Mucoid variation in Pseudomonas aeruginosa induced by the action of phage. Journal of Medical Microbiology 6, 111118.

Matsumoto, H., OHta, S., Kobayashi, R. \& TerawakI, Y. (1978). Chromosomal location of genes participating in the degradation of purines in Pseudomonas aeruginosa. Molecular and General Genetics 167, 165-176.

Phillips, I. (1969). Identification of Pseudomonas aeruginosa in the clinical laboratory. Journal of Medical Microbiology 2, 9-16.

STANISICH, V. (1974). The properties and host-range of male-specific bacteriophages of Pseudomonas aeruginosa. Journal of General Microbiology 84, 332-342.

Stanisich, V. \& Holloway, B. W. (1969). Conjugation in Pseudomonas aeruginosa. Genetics 61, 327339.

Stanisich, V. \& Holloway, B. W. (1972). A mutant sex-factor of Pseudomonas aeruginosa. Genetical Research 19, 91-108.

Vogel, H. J. \& BonNer, D. M. (1956). Acetylornithinase in Escherichia coli: partial purification and some properties. Journal of Biological Chemistry 218, 97-106.

Williams, R. J. \& Govan, J. R. W. (1973). Pyocine typing of mucoid strains of Pseudomonas aeruginosa isolated from children with cystic fibrosis. Journal of Medical Microbiology 6, 409-412. 